\title{
Antimicrobial Activity of 2-Nitro-6-[(4-Phenyl-Benzo[4,5]imidazo[1,2-a] Pyrimidin-2-ylimino)-Methyl]-Phenol: A Novel Schiff Base Compound
}

\begin{abstract}
Fonkui Thierry Youmbi, Oladeji Olatunde Sunday, Ikhile Itohan Monisola, Njobeh Patrick Berka, Muganza Munyololo
\end{abstract} Freddy, Fotsing Djuidje Marthe Carine and Ndinteh Tantoh Derek

\begin{abstract}
Nitro-6-[(4-phenyl-benzo[4,5]imidazo[1,2-a]pyrimid in-2-ylim ino)-methyl]-phenol (LH1), a novel Schiff base compound with benzimidazole moiety was successfully synthesized and characterized using UV-VIS light, FTIR, ${ }^{1} \mathrm{H}$ and ${ }^{13} \mathrm{C}$ NMR. The compound was screened for its antifungal and bactericidal properties against seven fungal strains and twelve pathogenic bacteria. Disc diffusion method was used for antifungal activity and broth microdilution technique was used to determine the minimum inhibitory concentration (MIC). The compound showed strong inhibitory growth property against all fungal strains than

reference material amphotericin B. Fusarium verticillioides was the most sensitive fungus with $18 \mathrm{~mm}$ diameter of the inhibition zone. Gram-positive bacteria were more sensitive to LH1 compared to Gram-negative. LH1 showed more potent activity inducing bacteria cell death than the controls particularly with Bacillus cereus (MIC 7.8 $\mu \mathrm{g} / \mathrm{mL}$ ) against streptomycin and nalidixic acid (MIC $512 \mu \mathrm{g} / \mathrm{mL}$ ). We conclude that LH1 has a low tolerance to these microbes, and promise to be a better remedy against their metabolic expressions
\end{abstract}

Keywords - Antibacterial, antifungal, antimicrobial benzimidazole, Schiff base

Manuscript received May 31st, 2017. This work was supported in part by the Global Excellence and Stature (GES) Master's and Doctorate Scholarships University of Johannesburg, South Africa.

Fonkui Thierry Youmbi is with the Department of Biotechnology and Food Technology University of Johannesburg, P.O. Box 17011, Doornfontein, Campus 2028, South Africa (e-mail: thierryfy@uj.ac.za).

Oladeji Olatunde Sunday is with the Department of Applied Chemistry,

University of Johannesburg P.O. Box 17011, Doornfontein Campus 2028, South Africa. (e-mail: oladeji.evans@ gmail.com)

Ikhile Itohan Monisola is with the Department of Applied Chemistry, University of Johannesburg P.O. Box 17011, Doornfontein Campus 2028,

South Africa (e-mail: mikhile@uj.ac.za).

Njobeh Patrick Berka is with the Department of Biotechnology and Food

Technology University of Johannesburg, P.O. Box 17011, Doornfontein, Campus 2028, South Africa. (e-mail: pnjobeh@uj.ac.za).

Muganza Munyololo Freddy is with the Department of Chemistry, Sefako, Makgatho Health Sciences University, Molotlegi Street, Ga-Rankuwa 0204,

Pretoria, South Africa.(e-mail: munyololom@gmail.com).

Fotsing Djuidje Marthe Carine is with the Department of Applied Chemistry, University of Johannesburg P.O. Box 17011, Doornfontein Campus 2028, South Africa. (e-mail: martasalem2005@yahoo.fr)

Ndinteh Tantoh Derek is with the Department of Applied Chemistry,University of Johannesburg P.O. Box 17011, Doornfontein Campus 2028, South Africa. (E-mail: dndinteh@uj.ac.za).

\section{INTRODUCTION}

The screening for antimicrobial agents to target human pathogenic bacteria and the major food contaminants (fungi) remain growing challenges because of microbes resisting drugs currently in use. Microorganisms through the process of adaptation have developed some forms of resistances against antibiotics and as such turned to nullify the efficacy of reference drugs. The lost in human and animal foods due to bacterial and fungal contamination registered per annum is of worldwide concern. Details on the contamination of agricultural products by toxigenic fungi and the hazard of ingesting the contaminated food products are available [1]; [2]; [3] and the need to feed the current 7.4 billion lives demand insight into food security and food safety.

Azomethines or imines $(\mathrm{C}=\mathrm{N}-)$ are carbon-nitrogen double bond compounds found in some naturally occurring molecules and can also be obtained by the condensation of a carbonyl and a primary amine as initially reported by Hugo Schiff [4]. Known as Schiff bases, imine properties have attracted scientists globally due to their multifaceted applications. Schiff bases have found interest in chemistry, biology, physic and the medical fields [5]; [6]; [7]; [8]. Schiff bases are amongst the most widely used organic molecules globally. The ease synthesis of Schiff bases by either condensation of primary amines with carbonyls in hot alcoholic solution, microwave assisted method or in water have been made known [9]; [10]. These have resulted in hundreds of thousands of compounds with diverse applications. In the search for novel Schiff base compounds with pharmacological properties, heterocycle derived Schiff bases have pointed out as better candidates and particularly those with benzimidazole moiety.

Benzimidazole is a nitrogen-based heterocyclic compound made of the fusion of a benzene ring and imidazole ring (Fig. 1). This compound is an important intermediate for the development of molecules of biological interest because of the inbuilt bioactive pharmacophore imidazole [11]. 


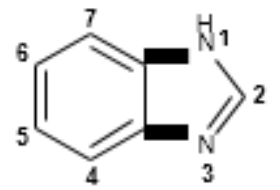

Fig. 1. Chemical structure of $1 H$-Benzimidazole

Incorporation of imidazole to benzene provides enough electron withdrawal to the molecule, which increases its nucleophilic property and allows substitution at different positions on the ring. Today it is a moiety of choice which possesses many biological applications and clinical properties [12]. Several derivatives of benzimidazole have been recorded together with their biological importance [13]. Benzimidazole and its derivatives have the capacity to interfere several microbial metabolic processes that in turn affect their growth

and sometimes leading to cell death. They have shown good activity against bacteria [14], fungi [15], virus [16], parasites [4]. They also have good anti-inflammatory property [17] and are also good antioxidant agents [18]. Despite these remarkable inputs made globally and the continuous microbial resistance, the demand for more efforts to attend these challenges is increasing. In this study, we report the synthesis, characterization and the antimicrobial activity which include the antifungal and bactericidal activity of a novel Schiff base compound with benzimidazole moiety.

\section{MATERIAL AND METHODS}

\section{A. Material}

Standard grade chemicals and reagents were used throughout in this study. The starting material compound $\mathbf{1}$ was donated to us by Dr. Ndinteh Derek Tantoh from the Department of Applied Chemistry University of Johannesburg. Detailed information on compound $\mathbf{1}$ is found here [19]. 2-Hydroxy-3-nitrobenzaldehyde, ethanol, and other solvents were obtained from Sigma-Aldrich South Africa. The microorganisms used were purchased from Davies Diagnostic South Africa and glycerol stocks were prepared and stored at -8 ${ }^{\circ} \mathrm{C}$.

\section{B. Physical Measurements}

The melting point of compound LHI was recorded on a hot stage electrothermal digital melting point apparatus with a maximum heating capacity of $450{ }^{\circ} \mathrm{C}$. Fourier transform infrared (FTIR) spectrum was collected using a Spectrum 100, PerkinElmer FTIR spectrophotometer with a CsI disc in the frequency range of 4000-200 $\mathrm{cm}^{-1}$. Optical measurement of the Schiff base was recorded on UV-2540 Shimadzu UV-Vis absorption spectrophotometry. The absorption was recorded between 200-800 nm. Flash 2000 organic elemental analyzer was used to determine the percentage of $\mathrm{C}, \mathrm{H}, \mathrm{N}$ contains in compound LH1. Structure elucidation by ${ }^{1} \mathrm{H}$ NMR and ${ }^{13} \mathrm{C}$ NMR was assessed on a Bruker $400 \mathrm{MHz}$ spectrometer apparatus operating at room temperature. Chemical shift values $(\delta)$ are given in ppm (parts per million) and deshield internally from tetramethylsilane (TMS).

\section{Synthesis of Schiff Base Ligand LHI}

Compound LH1 was synthesized as described by Yousif et al. [20] as shown below (Scheme. 1.). Compound 1 (50 mg: 18 mmol) was mixed with a solution of compound $\mathbf{2}$ in an equimolar ratio (1:1) and refluxed in ethanol for 4 hours. The yellow solution obtained was concentrated at low pressure on a rotary pump. The resulting precipitate was washed with cold ethanol, air dried and maintained from moisture in a desiccator.

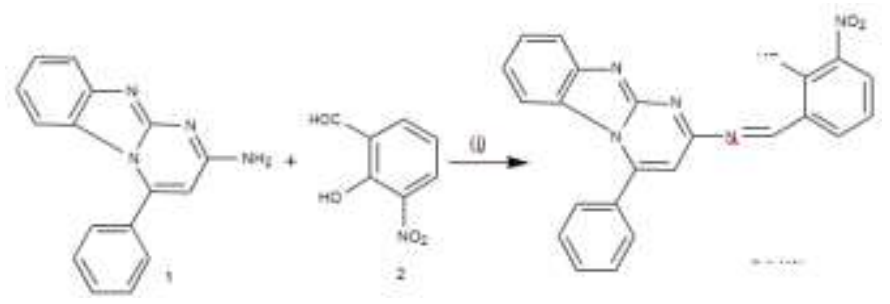

Scheme. 1. Synthesis of LH1

2-Nitro-6-[(4-phenyl-benzo[4,5] imidazo[1,2-a]pyrimidin-2yl imino)-methyl]-phenol(LH1)

LH1, (79\% yield); yellowish powder, $\mathrm{mp}=149^{\circ} \mathrm{C}$; FTIR $\left(\mathrm{cm}^{-1}\right): 3676,2991,1759,1558,1292,1052,921,766 ;{ }^{1} \mathrm{H}$ NMR $\left(400 \mathrm{MHz}, \mathrm{DMSO}-\mathrm{d}_{6}\right) \delta=10.24(1 \mathrm{H}, \mathrm{s}, \mathrm{OH}), 8.16(1 \mathrm{H}, \mathrm{s}$, $\mathrm{CH}=\mathrm{N}-), 8.05(1 \mathrm{H}, \mathrm{d}, \mathrm{J}=8.0 \mathrm{~Hz}, \mathrm{Ar}-\mathrm{H}), 7.78(1 \mathrm{H}, \mathrm{d}, \mathrm{J}=8.0 \mathrm{~Hz}$, Ar-H), 7.68-7.67 (3H, m, Ar-H), 7.56 (1H, d, J 8.0 Hz, Ar-H), $7.35(2 \mathrm{H}, \mathrm{t}, \mathrm{J}=8.0 \mathrm{~Hz}, \mathrm{Ar}-\mathrm{H}), 6.96(1 \mathrm{H}, \mathrm{t}, \mathrm{J}=8.0 \mathrm{~Hz}, \mathrm{Ar}-\mathrm{H}), 6$. $60(1 \mathrm{H}, \mathrm{t}, \mathrm{J}=8.0 \mathrm{~Hz}, \mathrm{Ar}-\mathrm{H}), 6.38(1 \mathrm{H}, \mathrm{s}, \mathrm{Ar}-\mathrm{H}), 6.17(1 \mathrm{H}, \mathrm{d}, \mathrm{J}=$ $8.0 \mathrm{~Hz}, \mathrm{Ar}-\mathrm{H}) .{ }^{13} \mathrm{C}$ NMR (400 MHz, DMSO-d 6 ) $\delta=191.1$, $161.8,161.3,151.0,148.4,134.9,132.2,131.4,131.3,129.4$, 128.6, 127.8, 126.8, 125.5, 121.1, 114.7, 113.3, 113.0, 101.6. Anal. Calcd for $\mathrm{C}_{23} \mathrm{H}_{15} \mathrm{~N}_{5} \mathrm{O}_{3} \%$ : C,54.29; H, 3.60; N, 10.55; Found: C,54.84; H, 3.48; N,10.58.

\section{Biological Assays}

\section{Bactericidal Activity}

Twelve pharmaceutical strains of bacteria were used to assess the bactericidal property of ligand LH1. The studied microbes include Gram positive (Bacillus cereus (ATCC10876), Bacillus subtilis (ATCC19659), Enterococcus faecalis (ATCC13047), Mycobacterium smegmatis (MC2155), Staphylococcus epidermidis (ATCC14990) and Gram-negative Escherichia coli (ATCC25922), Enterobacter cloacae (ATCC13047), Klebsiella oxytoca (ATCC8724), Klebsiella pneumonia (ATCC13882), Proteus vulgaris (ATCC6380), Pseudomonas aeruginosa (ATCC27853), Enterobacter aerogenes (ATCC13048). Broth microdilution method was followed as recommended here [21]. From an overnight bacterial culture prepared in nutrient broth, a suspension of $1.5 \times 10^{8} \mathrm{cfu} / \mathrm{mL}$ in Muller-Hilton corresponding to the $0.5 \mathrm{McF}$ arland standard was made ready. LH1 was dissolved in DMSO to contain $1 \mathrm{mg} / \mathrm{mL}$ stock solution. This was then serially diluted to give 500, $250,125,62.5,31.2,15.6$ and $7.8 \mu \mathrm{g} / \mathrm{mL}$ of which $100 \mu \mathrm{L}$ of each was seeded in duplicate in 96 well plates and flooded with $100 \mu \mathrm{L}$ of inoculum. The mixture was then incubated at $37^{\circ} \mathrm{C}$ in $5 \% \mathrm{CO}_{2}$ for 24 hours. Streptomycin and nalidixic acid were used as reference drugs for comparison. The amount of bacteria that resisted LH1 exposure was determined calorimetrically in resazurin dye. The minimum inhibitory concentration was 
recorded as the smallest concentration that induced bacterial cell death.

\section{E. Antifungal Activity}

The synthesized compound LH1 was evaluated through a preliminary in vitro antifungal screening activity against seven fungal strains (Aspergillus niger, Aspergillus fumigatus, Aspergillus flavus, Aspergillus parasiticus, Aspergillus carbonarius, Fusarium proliferatum, and Fusarium verticillioides). Disc diffusion method by CLSI [21] standard M28 was followed. Each fungal strain was allowed to produce spores after seven days incubation on potatoes dextrose agar (PDA). The spores were then harvested in Ringer solution and diluted to contain $1 \times 10^{5}$ spores $/ \mathrm{mL}$ working solution. Sterile blank discs $(6 \mathrm{~mm} \phi)$ were impregnated with $20 \mu \mathrm{L}$ of $1 \mathrm{mg} / \mathrm{mL}$ of test compound LH1 and placed in triplicate on solidified fresh PDA spread with $500 \mu \mathrm{L}$ of inoculum. The plates were incubated for 72 hours at $37{ }^{\circ} \mathrm{C}$. Amphotericin B and nystatin were used as positive controls. The effect of LH1 on fungal growth was observed and the diameters of the inhibition zones were measured in millimeter (mm) and compared with commercial standards.

\section{RESULTS AND DISCUSSION}

\section{A. Spectroscopy Data}

Schiff base compound LH1 was obtained by condensation reaction of starting materials $\mathbf{1}$ and $\mathbf{2}$ refluxed in hot ethanol for 4 hours. The yellow solution obtained was dried out and the Resulting yellow precipitate was washed with cold ethanol. The compound is stable in the air and has a high melting point (149 $\left.{ }^{\circ} \mathrm{C}\right)$. LH1 is soluble in DMSO and in hot ethanol however it precipitates in cold ethanol and it insoluble in methanol and chloroform. Electronic spectral of LH1 in DMSO showed absorption bands in the low UV range between 200-400 $\mathrm{nm}$. The two strong maxima were observed at $275 \mathrm{~nm}$ and $316 \mathrm{~nm}$. These absorption bands were assigned to the $\pi-\pi^{*}$ and $n^{---} \pi^{*}$ respectively. The first transition $\left(\pi-\pi^{*}\right)$ at $275 \mathrm{~nm}$ resulted from to the phenolic ring resonance while the second ( $\left.\mathrm{n} \pi^{*}\right)$ corresponds to the imine bond [22].

Infrared spectrum (FTIR) of LH1 showed a low or weak intensity band at $3676 \mathrm{~cm}^{-1}$ due to the phenolic $\mathrm{OH}$ group. The spectrum showed a sharp absorption signal at $1558 \mathrm{~cm}^{-1}$ corresponding to the $\mathrm{C}=\mathrm{N}$ vibration mode. Similar results are published here [23] confirming the successful formation of the azomethine bond. The stretching vibration at $2991 \mathrm{~cm}^{-1}$ was conferred to the $\mathrm{vC}-\mathrm{H}$ vibration frequency of the phenyl ring [24].

The percentage composition of $\mathrm{C}, \mathrm{H}$, and $\mathrm{N}$ contain in $\mathrm{LH} 1$ was determined theoretically and compared with experimental findings. Data showed that calculated values matched experimental results with \pm 0.5 units. These observations satisfied our expectations.

The structure of the title compound was confirmed using ${ }^{1} \mathrm{H}$ And ${ }^{13} \mathrm{C}$ NMR analysis. In the ${ }^{1} \mathrm{H}$ NMR spectrum showed a strong signal at $\delta=8.16 \mathrm{ppm}$ appearing as a singlet which was assigned to the imine $\mathrm{C}=\mathrm{N}-\mathrm{H}$ proton. Phenolic proton $(\mathrm{Ar}-\mathrm{OH})$ appeared at $\delta=10.24 \mathrm{ppm}$ with reference to the degree of the downfield medium. Aromatic protons are peaked as doublet (d), doublet the double (dd), triplet (t), and multiplet $(\mathrm{m})$ signals at $\delta$ $=6-8.03 \mathrm{ppm}$ with a coupling constant $J=8 \mathrm{~Hz}$. No undesired proton was recorded on the spectrum. ${ }^{13} \mathrm{C}$ NMR spectrum of the prepared Schiff base LH1 showed characteristic signals of imine and aromatic carbon atoms in the expected ranges of chemical shift values. At $\delta=161.85$ and $\delta=161.35 \mathrm{ppm}$, the imine groups $(\mathrm{C}=\mathrm{N}-\mathrm{C})$ and $(\mathrm{C}=\mathrm{N}-\mathrm{H})$ are observed. All carbons of the aromatic rings were observed between $\delta=101-155 \mathrm{ppm}$ [25]. The signal seen at $\delta=191.12 \mathrm{ppm}$ assigned to the $(\mathrm{N}=\mathrm{C}-\mathrm{N}=\mathrm{C}-\mathrm{H})$ appeared downfield as a result of the electronegativity of the $\mathrm{N}$ atom together with a free electron density of the aromatic rings.

\section{B. Biological Data}

\section{Bactericidal Activity}

Antimicrobial activity by broth microdilution method of compound LH1 against Gram-positive and Gram-negative bacteria was studied. The tested organisms were all sensitive to LH1 and the minimum inhibitory concentrations are summarized in Table. 1. We clearly see that the ligand has a low tolerance for Gram-positive bacteria (MIC $7.8 \mu \mathrm{g} / \mathrm{mL}$ ) compared to Gram-negative $(15.6 \mu \mathrm{g} / \mathrm{mL})$ affecting more the former. The compound exhibited strong activity against some pathogenic strains with greater potency than the reference drugs particularly Bacillus cereus (MIC $7.8 \mu \mathrm{g} / \mathrm{mL}$ ) against standards (MIC $32 \mu \mathrm{g} / \mathrm{mL}$ ). This makes LH1 compound four times more potent than streptomycin and nalidixic acid. Moreover, Mycobacterium smegmatis MIC $31.2 \mu \mathrm{g} / \mathrm{mL}$ against nalidixic acid MIC $512 \mu \mathrm{g} / \mathrm{mL}$ proved LH1 to be sixteen times strongly active than the control against the bacterium. The potency of LH1 to induce cell death in Gram-negative bacteria was observed against Escherichia coli and Enterobacter cloacae with MIC $250 \mu \mathrm{g} / \mathrm{mL}$ and $15.6 \mu \mathrm{g} / \mathrm{mL}$ respectively against commercial drugs (MIC $512 \mu \mathrm{g} / \mathrm{mL}$ ). These results, therefore, suggest that the compound can be considered as a candidate drug for the treatment of infections caused by these pathogens.

The cell walls of bacteria are made of lipids that regulate and control the flow of molecules in or outside the cells. The passage of molecules/ions across the cell membrane is polarity dependent. Lipids based membranes will interact better with lipid soluble compounds, therefore, favor their penetration into the cytoplasm. Lipophilicity $(\operatorname{cog} P)$ is an important factor for controlling the antimicrobial activity of target drugs was determined theoretically to be $\operatorname{cog} P=5.37$. This high value could also be the reason behind the strength of compound LH1. Because high lipophilicity generally leads to compounds with high rapid turnover [26], this increases the chemical interaction between the compound and bilayer membrane. As lipophilicity increases so are the cells membrane permeability which might result in an alteration in cellular metabolic activity leading to cell death. The hydrophobic core of the LH1 could also be associated with its aromatic rings which allow lipid solubility 
and consequently facilitates its passage across the cell membrane. [27].

TABLE I: DiAMETER (MM) OF ZONE OF INHIBITION OF LIGAND LH1, AMPHOTERICIN B AND NYSTATIN ( $\mu$ G/ML)

\begin{tabular}{|c|c|c|c|c|c|c|c|c|c|c|c|c|}
\hline \multicolumn{13}{|c|}{ Bacteria } \\
\hline \multirow[t]{2}{*}{ Test compounds } & \multicolumn{5}{|c|}{ Gram-positive } & \multicolumn{7}{|c|}{ Gram-negative } \\
\hline & BS & EF & SE & BC & MS & EC & PV & KO & $\mathbf{E A}$ & $\mathbf{P A}$ & $\mathbf{K P}$ & EC \\
\hline STM & 16 & 128 & 8 & 32 & 4 & 64 & 0.032 & 16 & 16 & 8 & 64 & 512 \\
\hline NLD & 16 & 512 & 64 & 32 & 512 & 512 & 0.008 & 8 & 256 & 64 & 64 & 16 \\
\hline
\end{tabular}

STM: Streptomycin; NLD: Nalidixic acid; BC: Bacillus cereus, BS: Bacillussubtilis, EF: Enterococcus faecalis, MS: Mycobacterium smegmatis, SE: Staphylococcus epidermidis, ECL: Enterobacter cloacae, EC: Escherichia coli, EA: Enterobacter aerogenes, PV: Proteus vulgaris, KO: Klebsiella oxytoca, KP: Kebsiella pneumonia, and PA: Pseudomonas aeruginosa
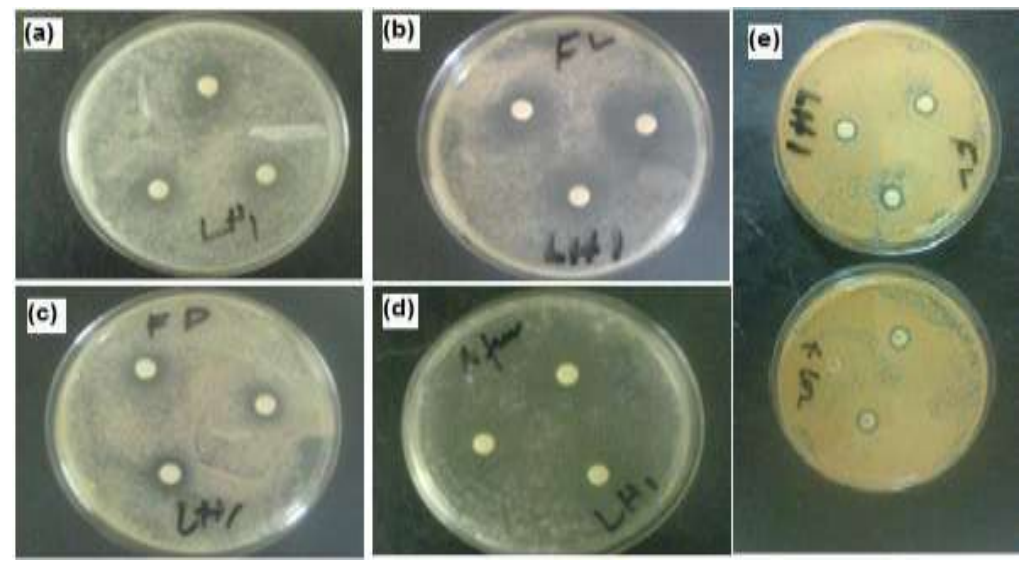

Fig. 1. Photography images showing the area of inhibition exhibited by ligand LH1 against (a) Aspergillus flavus, (b) Fusarium verticillioides, (c) Fusarium proliferatum, (d) Aspergillus fumugatus, and (e) Fusarium verticillioides against amphotericin B and nystatin standards (20 $\mu \mathrm{g}$ ).

(Here $20 \mu \mathrm{L}$ of LH1 corresponding to $20 \mu \mathrm{g}$ of $\mathrm{LH}_{1}$ was impregnated on each disc in triplicate)

\section{Antifungal Activity}

Disc diffusion assay was used to assess the antifungal activity of ligand LH1 against seven fungal strains. Sterile blank discs were soaked with $20 \mu \mathrm{L}$ of test compound containing $20 \mu \mathrm{g}$ of the analyte and placed on solidified PDA conditioned with $1 \mathrm{x}$ $10^{5}$ spores/mL of each fungus. Compound 1 affects the ease propagation of all fungi, inhibiting their growth as seen in Fig. 2. The compound has greater activity against the references materials used. The clear zones (no growth) around the discs were measured diagonally and the average values are summarized in Table. II. together with commercial drugs as diameters of inhibitory zones.

TABLE II: DIAMETER (MM) OF ZONE OF INHIBITION OF LIGAND LH1, AMPHOTERICIN B (AMB) AND NYSTATIN (NYT)

\begin{tabular}{llll}
\hline \multicolumn{3}{c}{ AMPHOTERICIN B (AMB) AND NYSTATIN (NYT) } \\
\hline & Sample & \multicolumn{1}{c}{ Standards } \\
\hline Fungal strains & LHI & AMB & Nystatin \\
\hline Aspergillus carbonarius & 13 & $\sim$ & 6 \\
\hline Aspergillus flavus & 14 & 10 & 12 \\
\hline Aspergillus fumigatus & 16 & 9 & 14 \\
\hline Aspergillus niger & 13 & 10 & 17 \\
\hline Aspergillus parasiticus & 15 & $\sim$ & 12 \\
\hline Fusarium proliferatum & 16 & 7 & 7 \\
\hline Fusarium verticillioides & 18 & 7 & 14 \\
\hline
\end{tabular}

Compound LH1 has strong antifungal activity against all the tested fungal strains and in some cases greater than the positive controls studied. The compound showed greater activity than amphotericin B. The compound LH1 displayed the highest activity against Fusarium verticillioides (Fig. 1 (b)) followed by Fusarium proliferatum (Fig. 1 (c) and Aspergillus fumigatus (Fig. 1 (d). The lowest activity of LH1 was noted against Aspergillus niger (Fig. not shown) yet with a diameter $(\phi 10$ $\mathrm{mm})$ higher than that of standard amphotericin $\mathrm{B}(\phi 8 \mathrm{~mm})$. Compound LH1 has a broader spectrum of activity exhibiting more strength against amphotericin B resistant strains like Aspergillus carbonarius and Aspergillus parasiticus with $\phi 13$ $\mathrm{mm}$ against $0 \mathrm{~mm}$ activity for AMB image not shown.

The antifungal activity of LH1 was similar to that of nystatin with slight differences. The potency of the compound can be explained by the similar reasons mentioned above. Though prokaryotic mechanisms of defense differ from fungi's and other large molecular genomes (eukaryotes), the same factors that control the movement of molecules in and outside the cells are maintained. The composition of bacteria cell membrane might differ from that of fungi but the major components are lipids and therefore the overturn theory [26] still applies.

\section{CONCLUSION}

A novel Schiff base compound LH1 with benzimidazole moiety was successfully synthesized, characterized, and studied for it antibacterial and antifungal properties. Spectroscopy data confirmed the structure of the ligand synthesized. The compound (LH1) showed strong antibacterial and antifungal activities against all the microorganisms tested. LH1 was cytotoxic to all bacterial strains analyzed in this study showing 
greater bactericidal potency than some reference materials. In addition, LH1 inhibits fungal growth far better than amphotericin B against all the fungi used, suggesting consideration of the compound as candidate remedy for these toxigenic fungi and pathogenic strains.

\section{REFERENCES}

[1] P. B. Njobeh, M. F. Dutton, S. H. Koch, A. A. Chuturgoon, S. D. Stoev, and J. S. Mosonik, "Simultaneous occurrence of mycotoxins in human food commodities from Cameroon," Mycotoxin Res., vol. 26, no. 1, pp. 47-57, Feb. 2010.

[2] L. Reddy and K. Bhoola, "Ochratoxins-Food Contaminants: Impact on Human Health,” Toxins, vol. 2, no. 4, pp. 771-779, Apr. 2010.

[3] J. Pitt, R. Plestina, G. Shepard, M. Solfrizzo, and P. . Verger, "Joint FAO/WHO Expert Committee on Food Additives (JECFA), Safety Evaluation of Certain Mycotoxins in Food. Geneve Switzeland," Food and Agricultural Organization, Geneva, p. 28, 2002.

[4] C. M. da Silva et al., "Schiff bases: A short review of their antimicrobial activities," J. Adv. Res., vol. 2, no. 1, pp. 1-8, Jan. 2011.

[5] S. Nag, A. Mishra, and S. Batra, "A facile route to the synthesis of pyrimido[2,1-b]quinazoline core from the primary allyl amines afforded from Baylis-Hillman adducts," Tetrahedron, vol. 64, no. 44, pp. 10162-10171, Oct. 2008.

[6] A. Kajal, S. Bala, S. Kamboj, N. Sharma, and V. Saini, "Schiff Bases: A Versatile Pharmacophore," J. Catal., vol. 2013, pp. 1-14, 2013.

[7] J. H. Tomma, M. S. Khazaal, and A. H. Al-Dujaili, "Synthesis and characterization of novel Schiff bases containing pyrimidine unit," Arab. J. Chem., vol. 7, no. 1, pp. 157-163, Jan. 2014.

[8] R. Alphonse, A. Varghese, and L. George, "Synthesis, characterization and photophysical studies of a novel schiff base bearing 1, 2, 4-Triazole scaffold," J. Mol. Struct., vol. 1113, pp. 60-69, Jun. 2016.

[9] B. T. Thaker and R. S. Barvalia, "Microwave assisted synthesis and characterization of unsymmetrical tetradentate Schiff base complexes of VO(IV) and $\mathrm{MoO}(\mathrm{V})$," Spectrochim. Acta. A. Mol. Biomol. Spectrosc., vol. 84, no. 1, pp. 51-61, Dec. 2011.

[10] S. Bhagat, N. Sharma, and T. S. Chundawat, "Synthesis of Some Salicylaldehyde-Based Schiff Bases in Aqueous Media," J. Chem., vol. 2013, pp. 1-4, 2013.

[11] P. Manocha, D. S. Wakode, A. Kaur, K. Anand, and H. Kumar, "A review: Imidazole synthesis and its biological activities," Int. J. Pharm. Sci. Res., vol. 1, no. 7, pp. 12-16, 2016.

[12] N. Srestha, J. Banerjee, and S. Srivastava, "A review on chemistry and biological significance of benzimidaole nucleus," IOSR J. Pharm., vol. 4, no. 12, pp. 28-41, 2014.

[13] N. Singh, A. Pandurangan, K. Rana, P. Anand, A. Ahamad, and A. kumar Tiwari, "Benzimidazole: A short review of their antimicrobial activities," Int. Curr. Pharm. J., vol. 1, no. 5, pp. 119-127, 2012.

[14] M. Noolvi, S. Agrawal, H. Patel, A. Badiger, M. Gaba, and A. Zambre, "Synthesis, antimicrobial and cytotoxic activity of novel azetidine-2-one derivatives of 1H-benzimidazole," Arab. J. Chem., vol. 7, no. 2, pp. 219-226, Apr. 2014.

[15] Salahuddin, M. Shaharyar, and A. Mazumder, "Benzimidazoles: A biologically active compounds," Arab. J. Chem., vol. 10, pp. S157-S173, Feb. 2017.

[16] K. Sztanke, A. Maziarka, A. Osinka, and M. Sztanke, "An insight into synthetic Schiff bases revealing antiproliferative activities in vitro," Bioorg. Med. Chem., vol. 21, no. 13, pp. 3648-3666, Jul. 2013.

[17] S. M. Sondhi, N. Singh, A. Kumar, O. Lozach, and L. Meijer, "Synthesis, anti-inflammatory, analgesic and kinase (CDK-1, CDK-5 and GSK-3) inhibition activity evaluation of benzimidazole/benzoxazole derivatives and some Schiff's bases," Bioorg. Med. Chem., vol. 14, no. 11, pp. 3758-3765, Jun. 2006.

[18] C. G. Neochoritis et al., "One-pot microwave assisted synthesis under green chemistry conditions, antioxidant screening, and cytotoxicity assessments of benzimidazole Schiff bases and pyrimido[1,2-a]benzimidazol-3(4H)-ones," Eur. J. Med. Chem., vol. 46, no. 1, pp. 297-306, Jan. 2011.

[19] H. Wahea et al., "Heterocycles of biological importance: Part 6. The formation of novel biologically active pyrimido[1,2-a]benzimidazoles from electron deficient alkynes and 2-aminobenzimidazoles," Arkivoc, vol. 2003, no. 14, p. 170, Dec. 2003.

[20] E. Yousif, A. Majeed, K. Al-Sammarrae, N. Salih, J. Salimon, and B. Abdullah, "Metal complexes of Schiff base: Preparation, characterization and antibacterial activity," Arab. J. Chem., 2013.

[21] CLSI, "Clinical, Laboratory Standards Institute. Reference method for broth dilution antifungal susceptibility testing of filamentous fungi, Second Edition: Approved Standard M38-A2. Wayne, PA, USA: CLSI; 2008.," Wayne PA, USA, 2008.

[22] A. A. Shanty, J. E. Philip, E. J. Sneha, M. R. Prathapachandra Kurup, S. Balachandran, and P. V. Mohanan, "Synthesis, characterization and biological studies of Schiff bases derived from heterocyclic moiety," Bioorganic Chem., vol. 70, pp. 67-73, Feb. 2017.

[23] K. Naresh Kumar and R. Ramesh, "Synthesis, luminescent, redox and catalytic properties of $\mathrm{Ru}(\mathrm{II})$ carbonyl complexes containing $2 \mathrm{~N} 2 \mathrm{O}$ donors," Polyhedron, vol. 24, no. 14, pp. 1885-1892, Oct. 2005.

[24] S. Thangavel, R. Rajamanikandan, H. B. Friedrich, M. Ilanchelian, and B. Omondi, "Binding interaction, conformational change, and molecular docking study of $\mathrm{N}$-(pyridin-2-ylmethylene)aniline derivatives and carbazole Ru(II) complexes with human serum albumins," Polyhedron, vol. 107, pp. 124-135, Mar. 2016.

[25] G. More, D. Raut, K. Aruna, and S. Bootwala, "Synthesis, spectroscopic characterization and antimicrobial activity evaluation of new tridentate Schiff bases and their Co(II) complexes," J. Saudi Chem. Soc., May 2017.

[26] H. van de Waterbeemd, D. A. Smith, K. Beaumont, and D. K. Walker, "Property-Based Design: Optimization of Drug Absorption and Pharmacokinetics," J. Med. Chem., vol. 44, pp. 1313-1333, Apr. 2001.

[27] M. Salehi et al., "Synthesis, characterization, structural study and antibacterial activity of the Schiff bases derived from sulfanilamides and related copper(II) complexes," Inorganica Chim. Acta, vol. 453, pp. 238-246, Nov. 2016 